\title{
An Investigation on Effectiveness of Resiliency Training on Assertive and Self-Esteem of Sixth-Grade Students
}

Iranian Evolutionary and Educational Psychology Journal June 2020: 110-119 (C) University of Hormozgan Publication 2020 DOI: 10.29252/ieepj.2.2.110 http://ieepj.hormozgan.ac.ir

\section{Ziaaldin Salari Koohfini' ${ }^{1}$, Manizhe Ghasemali Kheirabadi2 ${ }^{*}$}

\begin{abstract}
This study aimed to investigate effectiveness of resiliency training in enhancing assertive and self-esteem skills of male sixth-graders studying at all-boys elementary schools in Bandar Abbas. The present study was a pilot field project that included pre-test, post-test, and control group. Research sample consisted of 40 male sixth-graders studying at all-boys elementary schools who were selected and assigned into experimental and control groups based on multistage random sampling technique. Tools of this study included Gambrill-Richey Assertion Inventory and Coopersmith Self-Esteem Inventory and Both experimental and control groups had participated in assertive and self-esteem pretest prior to resiliency training. Then resiliency training was provided for experimental group, but not for control group. Immediately after the completion of training course, post-test was performed for both groups. The results of multivariate analysis of covariance (MANCOVA) showed that resiliency training increases students' self-assertion significantly. Therefore, it can be concluded generally that strengthening and training resiliency skills provoke assertive and self-esteem in students.
\end{abstract}

Keywords: training, resiliency, self-assertion, self-esteem, students.

\section{Introduction}

Despite profound cultural and lifestyle changes, in today's society many individuals lack the necessary and essential ability to cope with life's problems, and this has made them vulnerable to face problems of everyday life. Life skills are a set of skills and abilities that help individuals cope effectively and deal with difficult life situations and challenges. These abilities enable humans to act positively and adaptively in response to other humans, as well as their environment, society, and culture, and to ensure their mental health. In fact, self-scrutiny and effective and reciprocal communication with others are considered as basic goals of all educational systems (Ghani Far \& Kharaei, 2019).

Assertive is regarded as one of the most important factors for individuals' mental health, and in general, many behavioral problems are related to this variable. Any kind of deficiency in this skill will cause many problems for adolescents (Hadyian \& Dehghani, 2019).

As one of the most basic social skills, assertive has been defined in different ways. It refers to the path that

1. PhD Student in Curriculum, University of Hormozgan, BandarAbbas, Iran

*Corresponding author email: Salari_zia@yahoo.com

2. Master of Educational Psychology, Shahid Chamran University of Ahvaz, Ahvaz, Iran 
individuals take to assert or defend themselves and their rights as individuals. Individuals with high levels of assertive tend to be resilient and do not allow others to abuse them; and as a result, these individuals achieve a higher level of adaptation in social interaction. Assertive is a behavior that enables individuals to stand on their own feet without any anxiety, express their true feelings honestly, and assert themselves while respecting other people's rights (Sattari Sefidan Jadid, Rouholamini, \& Zare-Moghaddam, 2019).

Assertive is core of interpersonal behavior and key to human communications. According to (Alberti et al., 1977), assertive is regarded as a skill and competence in interpersonal relationships. Therefore, assertive training programs can improve information, beliefs, and some behaviors such as self-esteem, self-efficacy, general health, and assertiveness so that indiciduals can change their perspective and establish interpersonal relationships (Safari, 2019).

It is necessary to have self-esteem in order to acquire assertive skill and be able to defend and assert your rights. In fact, self-esteem is that kind of judgement that individuals make about themselves and usually maintain it. Self-esteem reflects an affirmative or non-affirmative attitude towards oneself (Coudevylle, Gernigon, $\&$ Ginis, 2011). Self-esteem and self-worth are among the most important factors in the optimal development of children's and adolescents' personalities. Self-esteem, as a central and fundamental factor in emotional-social adaptation, is regarded as one of the most important components of mental health (Jang \& Jeon, 2015). In general, several studies have shown that individuals with low self-esteem more likely experience low assertive compared to those with high self-esteem (Coudevylle et al., 2011) and individuals with higher self-esteem experience higher self-worth and a greater sense of confidence in their own skills in stressful situations, and this trust aids them to cope effectively with life's challenges (Ni et al., 2010).

On the other hand, research findings confirm that high self-esteem can affect academic performance, interpersonal communications, teamwork spirit, accomplishments, anger management and happiness, and improving these skills can be considered as a factor contributing to maintaining good mental health (Kia, Shabani, Ahghar, \& Modanloo, 2016).

Although the problem of low self-esteem and assertive is observed in all age groups, it is better to invest on children at an early age in order to prevent future problems due to the key role of assertive and self-esteem in the success and reduction of individuals' problems and it is also better to seek to equip individuals with these skills from an early age to increase their chances of success in life and prevent potential problems (Jang \& Jeon, 2015).

Resiliency is a technique used to increase assertive and self-esteem skills. Resiliency, as a process, is the ability of successfully adaptation despite threatening circumstances and, in other words, positive adaptation despite adverse conditions. Resiliency is considered as positive adaptation of a person in the face of adverse conditions (harm and threats). However, resiliency is not only perceived as being resilient to damages or threatening circumstances, and it is not regarded as a passive reaction to dangerous situations, it means active and productive involvement in your surroundings. Resiliency is one of the protective factors that combines with other protective factors and plays an important role in making individuals successful and helping them cope with adverse conditions. So students will behave adaptively when solving problems and will deal with problems easier if they have this characteristic (Jahedmotlagh, Younesi, Azkhosh, \& Farzi, 2015).

Heidarisharaf et al. (2019) examined the effectiveness of resiliency training in increasing the adaptation of newly arrived students living in dormitories and their research results showed that resiliency training increases 
the adaptation of students in experimental group with university, while such change is not observed in control group.

Moreover, Karami et al. (2019) conducted a study entitled "Effectiveness of Resiliency Training on Girl Students' Homesickness Reduction" and concluded that resiliency training has significantly reduced students' homesickness in experimental group, while such change was not observed in the subjects of control group. Another study titled "Effect of Resilience Education on Cognitive Appraisals, Coping and Emotions" was performed and its results indicated that resiliency training program was effective in increasing challenging and resource appraisals, proactive coping strategy and positive emotions and in decreasing threat appraisal and negative emotions of female students in short term and long term. Generally, findings of this study suggest that resiliency training program can realize the idea of mental immunization in students by strengthening positive thinking strategies, adaptive emotional management skills, as well as enriching interpersonal relationships skills (Mohebi, Shokri, \& Pourshahriar, 2018).

Browne et al. (2018) examined the effect of resiliency training on character strengths of individuals with first episode psychosis, and their results revealed that resiliency training can strengthen personal characters such as life satisfaction, courage, tranquility, transcendence, explicitness, honesty, kindness, generosity, justice, gratitude, humor, mental health, and interpersonal relationship.

Sood, Sharma, Schroeder, and Gorman (2014) worked on stress management and resiliency training among department of radiology faculty and concluded that there is a significant difference among subjects in experimental and control groups in terms of perceived stress, anxiety, quality of life, and mindful attention. However, no significant difference is reported in terms of resiliency between experimental and control groups. Given that the techniques used by highly resilient individuals increase the possibility of dealing constructively and effectively with the obstacles they face in the path of achieving their goals, and affects how they respond to these obstacles and considering the important role of assertive and self-esteem skills in achievements of students, the main aim of the present study is to address the effectiveness of resiliency training on assertive and self-esteem levels of sixth-graders in Bandar Abbas. The hypotheses of this research are:

1. Resiliency training increases assertive and self-esteem levels of students in experimental group compared to those in control group.

1.1. Resiliency training increases assertive level of students in experimental group compared to those in control group.

1.2. Resiliency training increases self-esteem level of students in experimental group compared to those in control group.

2. There is a significant relationship between assertive and self-esteem of sixth-graders in Bandar Abbas.

\section{Material and Method}

The present study was a pilot field project that included pre-test, post-test, and control group that did not receive intervention. There are an experimental and a control group in this study that are selected randomly and divided into two groups randomly. Statistical population of the present study consists of all male sixth-graders (i.e. 4566 students) studying at all-boys elementary schools in Bandar Abbas in 2017-2018 academic year. First, one district was selected out of two educational districts of Bandar Abbas using multistage random sampling technique. Then two schools were selected out of different schools located in District 1 and four 
sixth-grade classes were selected out of sixth grade classes of selected schools and 100 students were selected based on simple random sampling technique and research tools were provided for them. After questionnaires were collected, 40 participants with the lowest points on assertive and self-esteem scales were randomly selected and assigned into two experimental and control groups. Research tools include:

Gambrill-Richey Assertion Inventory: This questionnaire was developed by Gambrill and Richey (1975) and consists of forty items. Each item represents a situation and the respondents should specify their anxiety level and the likelihood of their response to each item. Mental disturbance level points out to the degree and intensity of respondents' anxiety and disturbance when facing these situations and behavior occurrence rate points out to the possibility of occurrence of such behaviors. Unlike other assertive inventories, Gambrill-Richey Assertion Inventory has not been developed for specific individuals, and its items cover a wide range of different situations. Gambrill and Richey reported that the reliability of this tool equals 0.81 . Rooz Tehran Psychiatric Institute reported that the reliability coefficient of the Iranian version of this tool equals 0.82 (Mahmoudi, Azeemi, \& Zarghami, 2004).

The present study also measured the reliability of this tool using Cronbach's alpha, Spearman-Brown Split Half Reliability coefficient, Guttman Split Half Reliability Coefficient and re-administration (after one month) and the results were $0.88,0.79,0.80$, and 0.77 , respectively. Also, concurrent validity of this tool and the assertion questionnaire developed by Yul Lee et al. was calculated to be 0.89 , and these results indicate good reliability and validity of this questionnaire.

Coopersmith Self-Esteem Inventory: Coopersmith Self-Esteem Inventory consists of 58 items measuring individual's feelings, beliefs, or reactions, and for every item, the respondents must provide an answer by choosing either "like me" or "not like me" choices. The overall score of this questionnaire makes it possible to identify the context in which individuals have a positive self-image. The reliability of this questionnaire was calculated to be 0.78 through Cronbach's alpha and its validity was calculated to be 0.76 using test score correlation method in the research conducted by Mirzaei, Babae, Alizadegan Moghadam, Mahmudi, and Shaghaghi (2017). The present study also measured the reliability of this tool using Cronbach's alpha, Spearman-Brown Split Half Reliability coefficient, Guttman Split Half Reliability Coefficient and re-administration (after one month) and the results were $0.81,0.78,0.80$, and 0.76 , respectively. Moreover, construct validity of this tool was calculated to be in the range of 0.73-0.81 through materials analysis method (a kind of construct validity that is measured using the correlation of each item with total score of questionnaire). These results indicate good reliability and validity of this tool.

\section{Research Method}

In order to carry out educational interventions, certification for doing research in selected schools was obtained after the researcher went to the Department of Education and then to different education districts. After this process, the researcher went to schools in order to brief the principals, teachers and students and then a pilot intervention was carried out. Since the sample of this study was selected from the students of two different schools, educational intervention was performed separately in each school (while observing the principle of equal implementation). Educational intervention was resiliency training that was performed in nine 90-minute sessions as a group work in an interactive manner. The summary of the training sessions is given in Table 1. 
Table 1. Summary of resiliency training sessions that students in experimental group received

\begin{tabular}{|c|c|}
\hline Sessions & Activities \\
\hline First session & $\begin{array}{l}\text { Introducing the program, group members, and the researcher, explaining the goal, rule, and group } \\
\text { framework }\end{array}$ \\
\hline Second session & Introducing stress concept, giving instruction on resiliency concept and resilient behaviors \\
\hline Third session & $\begin{array}{l}\text { Introducing stress coping strategies, and giving instruction on using proper and effective coping strat- } \\
\text { egies }\end{array}$ \\
\hline Fourth session & $\begin{array}{l}\text { Teaching cognitive restructuring technique and developing a resilient and constructive thinking model, } \\
\text { explaining the relationship among thought, behavior, and emotions, introducing Ellis's ABC model }\end{array}$ \\
\hline Fifth session & $\begin{array}{l}\text { Coming to phenomenological understand of stimulus and the role of negative self-talk and thoughts } \\
\text { in experiencing stress, challenging negative self-talk and thoughts, changing and replacing them with } \\
\text { positive and constructive self-talk and thoughts }\end{array}$ \\
\hline Sixth session & $\begin{array}{l}\text { Introducing Seligman's explanatory and thinking styles and their roles in enhancing resiliency, replac- } \\
\text { ing pessimistic thinking styles with optimistic ones, developing and maintaining optimistic explanato- } \\
\text { ry and thinking styles }\end{array}$ \\
\hline Seventh session & $\begin{array}{l}\text { Introducing encouragement, self-encouragement, discouragement, and emphasizing on purposeful } \\
\text { behavior }\end{array}$ \\
\hline Eighth session & $\begin{array}{l}\text { Introducing logotherapy approach and emphasizing on significant role of liberty and freedom to } \\
\text { choose your lifestyle }\end{array}$ \\
\hline Ninth session & Summarizing, reviewing, concluding and administering post-test \\
\hline
\end{tabular}

\section{Results}

Table 2 shows descriptive information about assertive and self-esteem variables in the present study. Multivariate analysis of covariance (MANCOVA) was performed on posttest scores of both groups while pretests of research dependent variables (assertive and self-esteem) had been controlled in order to investigate the first research hypothesis on the effectiveness of resiliency training on assertive and self-esteem skills of students and the results are presented in Table 3. It is worthy to note that the data related to hypotheses was investigated before data analysis just to ensure that the data of this study is suitable to estimate the underlying assumptions of the analysis of covariance. Therefore, four assumptions of analysis of covariance including linearity, multicollinearity, homogeneity of variance, and homogeneity of regression were investigated and all of them have been observed in this study.

Table 2. Mean and standard deviation of assertiveness and self-esteem in experimental and control groups by pre-test and post-test

\begin{tabular}{|c|c|c|c|c|c|}
\hline \multirow{2}{*}{ Variable } & Statistical indicators & \multicolumn{2}{|c|}{ Experimental group } & \multicolumn{2}{|c|}{ Control group } \\
\cline { 2 - 6 } & & Pre test & Post test & Pre test & 47.73 \\
\hline \multirow{3}{*}{ Assertiveness } & Mean & 47.26 & 67.13 & 4.02 & 47.1 \\
\cline { 2 - 6 } & SD & 3.93 & 3.02 & 18.05 & 20.04 \\
\hline \multirow{2}{*}{ Self-steem } & Mean & 17.76 & 30.06 & 18.74 & 1.98 \\
\cline { 2 - 6 } & SD & 2.48 & 2.37 & & \multicolumn{2}{|c|}{1} \\
\hline
\end{tabular}


Table 3. Summary of the results of multivariate analysis of covariance of dependent variables

\begin{tabular}{|c|c|c|c|c|c|c|c|}
\hline \multicolumn{2}{|c|}{ Effect } & value & F & Hypothesis df & Error df & sig & Effect size \\
\hline \multirow{5}{*}{ Group } & Pillais trace & 0.78 & 97.35 & 2 & 55 & 0.0001 & 0.78 \\
\cline { 2 - 8 } & Wilks lambda & 0.22 & 97.35 & 2 & 55 & 0.0001 & 0.78 \\
\cline { 2 - 8 } & Hotellings trace & 3.54 & 97.35 & 2 & 55 & 0.0001 & 0.78 \\
\cline { 2 - 8 } & Roys largest root & 3.54 & 97.35 & 2 & 55 & 0.0001 & 0.78 \\
\hline
\end{tabular}

Table 4. Results of one-way analysis of covariance in MANCOVA context on post-test scores of assertive and self-esteem variables

\begin{tabular}{|c|c|c|c|c|c|c|c|}
\hline \multirow{2}{*}{ Effect } & Dependent variable & SS & DF & MS & F & Sig. & Effect size \\
\hline \multirow{2}{*}{ group } & assertive & 4080.415 & 1 & 204.020 & 107.89 & 0.0001 & 0.65 \\
\cline { 2 - 9 } & Self-steem & 199.09 & 1 & 9.954 & 94.86 & 0.0001 & 0.62 \\
\hline
\end{tabular}

Contents of Table 3 indicate that there is a significant difference between the experimental and control groups in terms of at least one of dependent variables (i.e. assertive and self-esteem). One-way analysis of covariance in MANCOVA context was performed on dependent variables in order to examine this effect more closely. The results of this analysis are presented in Table 4 . The results displayed in Table 4 reveal that one-way analysis of covariance in assertive $(\mathrm{F}=107.89$ and $\mathrm{P}=0.0001)$ and self-esteem $(\mathrm{F}=94.86$ and $\mathrm{p}=0.0001)$ variables is significant. It is sufficient to compare the post-test mean scores of experimental and control groups in terms of the mentioned dependent variables in order to perceive this difference. Based on the results presented in Table 2, the post-test mean scores that experimental and control groups obtained for assertive equal 67.13 and 47.1, respectively indicating when pre-test is controlled, there is a significant difference between assertive of experimental and control groups. Moreover, the post-test mean scores that experimental and control groups obtained for self-esteem equal 30.06 and 20.04, respectively indicating when pre-test is controlled, there is a significant difference between self-esteem of experimental and control groups. Therefore, the first hypothesis of the research is accepted.

Pearson correlation coefficient has been used to investigate the second research hypothesis stating that there is a significant relationship between assertive and self-esteem skills of male sixth-graders studying at elementary schools in Bandar Abbas, and the results are displayed in Table 5.

Table 5. Pearson correlation coefficient results between the variables of assertiveness and self-esteem of students in the present study

\begin{tabular}{|c|c|c|c|c|}
\hline Row & Variables & 1 & 2 & Sig. \\
\hline 1 & Assertiveness & 1 & 0.69 & 0.001 \\
\hline 2 & Self-steem & 0.69 & 1 & 0.001 \\
\hline
\end{tabular}

The results of Table 5 show that there is a significant negative correlation between assertive and self-esteem of sixth-graders studying at elementary schools in Bandar Abbas and since the lower the score, the higher the assertion, significant negative correlation between the mentioned two variables means that the higher the assertion of sixth-graders in Bandar Abbas, the higher their self-esteem, and vice versa $(r=0.69)$. Therefore, the second research hypothesis is also accepted. 


\section{Discussion}

The present study used resiliency training program to increase assertion and self-esteem skills of male sixth-graders studying at all-boys elementary schools. The findings showed that there is a significant difference between pre-test and post-test of the experimental and control groups in terms of dependent variables (assertive and self-esteem). In other words, resiliency training program has led to an increase in assertive and self-esteem of students in experimental group. The findings of this study are in line with the results of research carried out by Heidarisharaf et al. (2019), Karami et al. (2019), Mohebi et al. (2018), Browne et al. (2018), and Sood et al. (2014) who found resiliency training improves and establishes positive psychological traits in individuals.

The effect of resiliency training on assertive can be explained based on the results of studied performed by Tavakoli and Andishmand (2016) and Shi, Wang, Bian, and Wang (2015) and it can be said that resiliency can be effective as one of the protective factors against future risk factors. In psychology, positive capacity of individuals to adapt to stress and disasters is called resiliency. Many researchers have described resiliency as a good idea, with high practical value, to help individuals cope with adversity and protect them from the dangers that arise during their lifetime (Letourneau, 2020) and consequences of lacking assertive skill, or in other words, lacking courage to assert their rights while respecting others' rights are among dangers that may threaten students. Resiliency training educates students on how to resist difficult situations and adapt to new situations in order to solve problems.

In fact, resiliency teaches individuals that they can escape unbearable conditions by saying no to demands that they do not want to fulfill; instead, individuals can establish conditions for themselves that gives them a sense of self-respect and wrathfulness. The reason for this could be the improvement of capabilities that may have received more attention during resiliency training programs. These capabilities include an increase in self-awareness, ability to say no, self-esteem, need for affiliation, purposefulness, self-efficacy (problem solving, decision making, accountability), emotion control and meaningfulness; because resiliency acts as a process of positive adaptation to adverse situations (Allen, Haley, Harris, Fowler, \& Pruthi, 2011) and in its newer perceptions it is considered as a dynamic military ability to resist or recover from significant challenges that threaten stability, life, and growth (Masten, 2012).

Golestani, Goodarzi Gandomkari, and Barjasteh (2016) also found that resiliency training will increase students' self-esteem. According to experts, resilient, remedial, and flexible individuals adapt to environmental changes and recover quickly after the stressor is eliminated. However, individuals with low resiliency slightly adapt to new situations, they slowly recover to normal and improve from stressful situations (Shi et al., 2015). Resiliency is a developmental skill that allows individuals to increase their efforts to achieve more success in the face of life's failures, disasters, contradictions, and even positive events, achievements, and responsibilities. Resiliency is believed to improve the ability to successfully adapt to threatening circumstances and challenges (Oshio, Kaneko, Nagamine, \& Nakaya, 2003), and resiliency training sessions enhanced students' self-esteem because they were educated on coming to phenomenological understand of stimulus and the role of negative thoughts and self-talk in experiencing stress, challenging negative thoughts and self-talk, changing and replacing them with positive and constructive thoughts and self-talk, replacing pessimistic thinking style with the optimistic one, establishing and maintaining optimistic thinking and explanatory styles, self-encouraging, emphasizing on purposefulness of behaviors, emphasizing on significant role of liberty and freedom to 
choose your life style.

The results of analyzing second research hypothesis stating there is a significant relationship between students' assertive and self-esteem also showed that there is a significant correlation between these two variables and students' assertive level increases when their self-esteem enhances. The results of analyzing this hypothesis are in line with the results of study carried out by (Golestani et al., 2016), and this finding reveals that many difficulties in daily life, such as shyness, embarrassment and shame, isolation and anxiety root in lack of assertive skill, courage, and assertiveness, and individuals establish a sense of self-efficacy and positive self-concept when they have assertive skill, because those with assertive skill are highly self-aware and have the courage to assert their rights as they are aware of their own rights and this will increase their self-esteem. Coopersmith came into conclusion that children with high self-esteem are individuals who feel independent, creative, and even self-controlled and self-assertive, and are not easily influenced by environmental factors. Conversely, psychological pathology suggests that many of traumatic behaviors of children at home and school including aggression, anxiety, delinquency, suicidal ideation, smoking, drug abuse, academic failure, irresponsibility, and low assertive root in lack of "self-esteem." In fact, the higher the individuals' self-belief and self-esteem, the higher their level of assertive and efficiency, and the more they will be protected from psychosocial harm (Mirhashemi \& Ganji, 2004). Self-esteem means the value or prestige that individuals attach to themselves; That is, one's opinion of oneself. Now this question arises: how this feeling is formed about oneself? This feeling develops through individuals' self-judgement of their own behavior, appearance, intelligence, social achievements, as well as through the feedback and judgement that they receives from others. Sometimes individuals' self-judgment is influenced by others' judgement. Therefore, our opinions about our good or bad traits including, behaviors, appearance, intelligence level, achievements and failures reflect and is interactively related to others' opinions about our behaviors, appearance, intelligence level and achievements or failures and form our self-esteem level. Obviously, those with poor self-esteem, lack confidence in their own talents and abilities, do not value themselves much, and cannot be highly self-assertive in public (Mirhashemi \& Ganji, 2004).

Like other studies, this study suffers from some limitations such as limited statistical population that includes only boys; therefore, the results cannot be generalized to all students. The other limitation is lack of control over events, except for experimental intervention, that occurred between pre-test and post-test. These events should be taken into consideration in future research. It is also suggested that this research be conducted on female students as well as the students of other grades and it is also recommended that workshops on resiliency training to students be held in schools.

\section{Declaration of Conflicting Interests}

The author(s) declared no potential conflicts of interest with respect to the research, authorship, and/or publication of this article.

Funding: The author(s) received no financial support for the research, authorship, and/or publication of this article.

Acknowledgements: We would like to thank all the participants for their cooperation in the study. 


\section{References}

Alberti, R., Emmons, M., Fodor, I., Galassi, J., Galassi, M., Garnett, L., . . Wolfe, J. (1977). A statement of principles for ethical practice of assertive behavior training. Assertivennes: Innovations. Aplications, Issues.

Allen, R. S., Haley, P. P., Harris, G. M., Fowler, S. N., \& Pruthi, R. (2011). Resilience: Definitions, ambiguities, and applications Resilience in Aging (pp. 1-13): Springer.

Browne, J., Estroff, S. E., Ludwig, K., Merritt, C., Meyer-Kalos, P., Mueser, K. T., . . Penn, D. L. (2018). Character strengths of individuals with first episode psychosis in Individual Resiliency Training. Schizophrenia research, 195, 448-454.

Coudevylle, G. R., Gernigon, C., \& Ginis, K. A. M. (2011). Self-esteem, self-confidence, anxiety and claimed self-handicapping: A mediational analysis. Psychology of Sport and Exercise, 12(6), 670-675.

Gambrill, E. D., \& Richey, C. A. (1975). An assertion inventory for use in assessment and research. Behavior Therapy, 6(4), 550-561.

Ghani Far, M. H., \& Kharaei, K. (2019). The Effectiveness of Life Skills Training (Self-Awareness and Effective Communication) on the Existence and Lack of Secondary School Students. Medical Journal of Mashad University of Medical Sciences, (62), 94-101.

Golestani, S., Goodarzi Gandomkari, S., \& Barjasteh, H. (2016). The Role of Assertive in Self-Esteem. The First International Conference on Humanities with Approach Native-Islamic, Tehran.

Hadyian, S., \& Dehghani, A. (2019). The Effectiveness of Acceptance and Commitment-Based Therapy on Assertiveness of Imposed War Veterans' daughters. Iranian Journal of War and Public Health, 11(3), 147-151.

Heidarisharaf, P., Karami, J., Ashteh, K., Mousavi, Z., Tarighatimaram, F., \& Yavari, M. (2019). Effectiveness of Assertive Training on Enhancing Girl Students'Adjustment. Rooyesh-e-Ravanshenasi Journal, 8(3), 187-194.

Jahedmotlagh, A., Younesi, J., Azkhosh, M., \& Farzi, M. (2015). The effect of training on psychological stress resiliency of female students living in dormitories. Journal of school psychology, 4(2), 7-21.

Jang, H.-J., \& Jeon, M.-K. (2015). Relationship between self-esteem and mental health according to mindfulness of university students. Indian Journal of Science and Technology, 8(21), 1.

Karami, J., Moosavi, Z., Tarighatimaram, F., Siahkamari, R., Yavari, M., \& Haidarisharaf, P. (2019). Effectiveness of resiliency training on girl student's homesickness reduction. Rooyesh-e-Ravanshenasi, 7(11), 45-56.

Kia, S., Shabani, H., Ahghar, G., \& Modanloo, M. (2016). The effect of assertiveness training on first-grade schoolgirls' self-esteem in Tehran. Iranian Journal of Psychiatric Nursing, 4(1), 38-46.

Letourneau, N. (2020). Fostering resiliency in infants and young children through parent-infant interaction. Parenting and Child Development: Issues and Answers, 27.

Mahmoudi, G., Azeemi, H., \& Zarghami, M. (2004). The effect of asserfive training on degree of anxiety \& assertiveness of nursing Students. J Gorg Univer Med Sci, 6(2), 66-72.

Masten, A. S. (2012). Resilience in children. Developmental Psychology: Revisiting the Classic Studies; SAGE Publications: London, UK, 204.

Mirhashemi, M., \& Ganji, M. (2004). A Practical Guide to Depression Treatment. Tehran: Virayesh. 
Mirzaei, J., Babae, R., Alizadegan Moghadam, L., Mahmudi, F., \& Shaghaghi, P. (2017). Investigation of the Effectiveness of Emotional Intelligence Training on the General Health and Self-Esteem in Adolescents with Cerebral Palsy. Empowering Exceptional Children, 8(2), 37-49.

Mohebi, S., Shokri, O., \& Pourshahriar, H. (2018). Effect of Resilience Education on Cognitive Appraisals, Coping and Emotions. Journal of Developmental Psychology, 15(57), 83-99.

Ni, C., Liu, X., Hua, Q., Lv, A., Wang, B., \& Yan, Y. (2010). Relationship between coping, self-esteem, individual factors and mental health among Chinese nursing students: A matched case-control study. Nurse education today, 30(4), 338-343.

Oshio, A., Kaneko, H., Nagamine, S., \& Nakaya, M. (2003). Construct validity of the adolescent resilience scale. Psychological reports, 93(3_suppl), 1217-1222.

Safari, M. R. (2019). A Study of Student-Teachers' Assertiveness From professors' view: Case Study of Farhangian University, Kermanshah Province. Rooyesh-e-Ravanshenasi Journal (RRJ), 8(2), 45-54.

Sattari Sefidan Jadid, K., Rouholamini, M. S., \& Zare-Moghaddam, A. (2019). Effectiveness of self-assertive training on teenagers with divorced parents. Rooyesh-e-Ravanshenasi Journal (RRJ), 7(10), 85-96.

Shi, M., Wang, X., Bian, Y., \& Wang, L. (2015). The mediating role of resilience in the relationship between stress and life satisfaction among Chinese medical students: a cross-sectional study. BMC medical education, 15(1), 16.

Sood, A., Sharma, V., Schroeder, D. R., \& Gorman, B. (2014). Stress Management and Resiliency Training (SMART) program among Department of Radiology faculty: a pilot randomized clinical trial. Explore, 10(6), 358-363.

Tavakoli, M., \& Andishmand, V. (2016). The Relationship between Alexithymia and Assertive with Assertive in Students Studying General Psychology at Islamic Azad University, Kerman Branch. Paper presented at the The First New Research National Conference on Psychology, Consulting Psychology, and Education Sciences, Tehran. 